\title{
Mitigation of 2,4-dinitrofluorobenzene-induced atopic dermatitis-related symptoms by Terminalia chebula Retzius
}

\author{
DONG-YOON NAM ${ }^{1 *}$, JIN-MAN LEE $^{2 *}$, JIN-CHUL HEO $^{3,4}$ and SANG-HAN LEE ${ }^{1,3}$ \\ ${ }^{1}$ Department of Food Science and Biotechnology, Kyungpook National University, Daegu 702-701; \\ ${ }^{2}$ Department of Food and Biotechnology, Hoseo University, Asan 336-795; ${ }^{3}$ Food and Bio-Industry \\ Research Institute, Kyungpook National University, Daegu 702-701, Republic of Korea
}

Received May 19, 2011; Accepted June 20, 2011

DOI: 10.3892/ijmm.2011.792

\begin{abstract}
To evaluate whether an aqueous seed extract of Terminalia chebula Retzius inhibited development of atopy in vivo, we used a 2,4-dinitrofluorobenzene (DNFB)-induced animal model of atopic symptoms to investigate the effects of the extract. We measured $\mathrm{CD} 4^{+}$cell numbers by hematoxylin and eosin (H\&E) staining, and determined the expression levels of matrix metalloproteinase (MMP)-9, interleukin (IL)-31, and T-bet genes, in this animal model. The data showed that a Terminalia chebula extract $(100 \mu \mathrm{g} / \mathrm{ml})$ exhibited strong anti-atopic activity, mediating a $52 \%$ reduction in the immune response, as measured by thickness of ear swelling, and resulting in decreased eosinophil levels in adjacent skin tissue. Collectively, the results indicate that a Terminalia chebula seed extract has potential for alleviation of atopy-like symptoms induced by DNFB in the mouse.
\end{abstract}

\section{Introduction}

It is generally accepted that the daily consumption of plantderived phytochemicals in vegetables, fruit, tea or herbal extracts may mitigate free-radical attacks (1-3). Terminalia chebula Retzius is an ethnopharmacological plant of India and Southeast Asia, and has traditionally been used as a laxative, a diuretic, and an anti-oxidative material (4-8). In addition, plant

Correspondence to: Dr Sang-Han Lee, Department of Food Science and Biotechnology, Kyungpook National University, 1370 SanGyukDong, BukGu, Daegu 702-701, Republic of Korea

E-mail: sang@knu.ac.kr

Present address: ${ }^{4}$ Pharmacology Research Center, Korea Research Institute of Chemical Technology, Daejon 305-600, Republic of Korea

*Contributed equally

Abbreviations: TcRSE, seed extract of Terminalia chebula Retzius; DNFB, 2,4-dinitrofluorobenzene; MMP, matrix metalloproteinase; IL, interleukin; H\&E, hematoxylin and eosin

Key words: Terminalia chebula Retzius, anti-atopic, DNFB, MMP-9, IL-31, T-bet extracts have antibacterial $(9,10)$, antiviral (11), antifungal (12) and immune modulatory activities $(13,14)$. Recently, Lee et al $(5,15)$ reported that an aqueous seed extract of Terminalia chebula Retzius (TcRSE) had potent anti-oxidant activity both in vitro and in vivo when tested as a hepatoprotective agent in an animal model.

Atopic dermatitis is a major degenerative disease, which presents as a chronic inflammatory skin condition with a deficiency in barrier function (16). It is now well recognized that several proteases, including the matrix metalloproteinases (MMPs), play key roles in the immunopathology of and biological functions during progression of the disease (17). With limited exceptions, normal healthy skin does not contain or exhibit high levels of MMP activity. Thus, evaluation of enzyme activities is important in detection, prior to mitigation, of allergic reactions $(18,19)$. However, little effort has been devoted to treatment of atopy-related disorders with natural extracts, and we thus prioritized the investigation of TcRSE as an inhibitor of anti-atopic dermatitis activity.

In the present study, we initially sought immunomodulatory components in natural resources including foods and oriental herbs, and found that TcRSE was active in vitro (data not shown). We thus examined the ameliorating effects of TcRSE against 2,4-dinitrofluorobenzene (DNFB)-induced atopic dermatitis in mice. Biochemical and immunochemical analyses, including cytokine expression evaluation and phenotypic atopic symptoms, were performed to investigate whether TcRSE alleviated the disorder.

\section{Materials and methods}

Chemicals. MMP-9, anti-T-bet and interleukin (IL)-31 antibodies were purchased from Cell Signaling (catalog no. 3852; Danvers, MA), Santa Cruz Biochemicals (catalog no. 4B10; Santa Cruz, CA), and AnaSpec (Fremont, CA), respectively. The cell viability assay kit (CCK-8) was from Dojindo (Tokyo, Japan). 2,4-Dinitrofluorobenzene (DNFB), formalin, hydrogen peroxide (all from Sigma, St. Louis, MO), and all other materials were of the highest grade commercially available.

Animals. Male C57BL/6 mice 6-7 weeks of age were purchased from Samtaco (Osan, Korea). Animals were housed in an airconditioned room, at a temperature of $22 \pm 1^{\circ} \mathrm{C}$ and a humidity of 
A

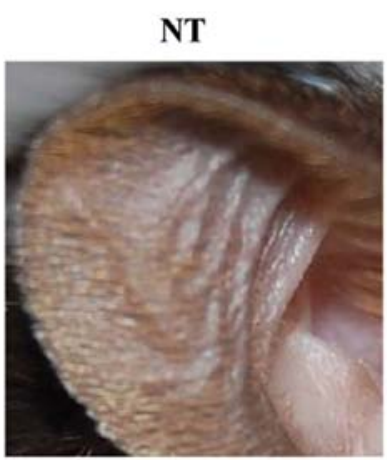

B

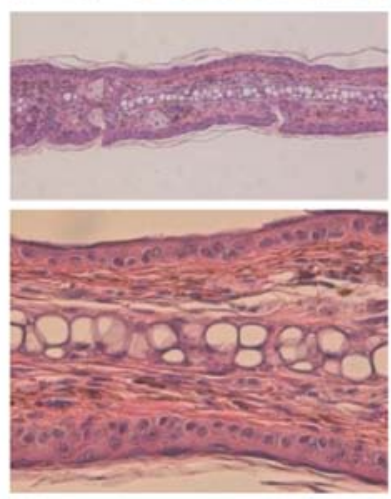

$0.2 \%$ DNFB

$(-)$
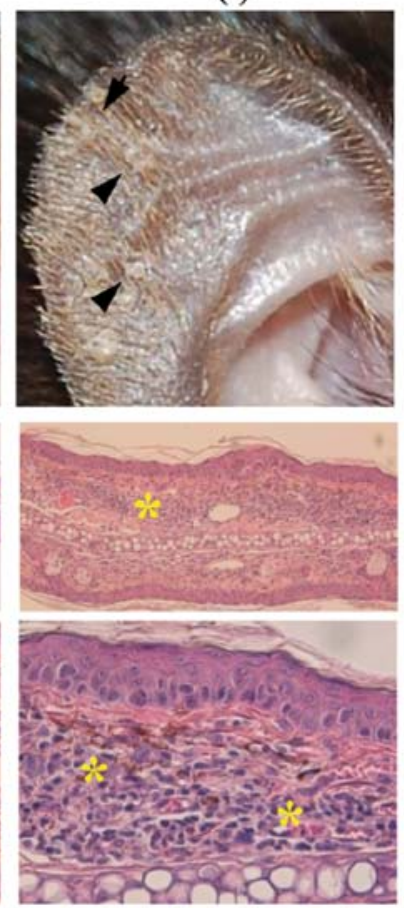
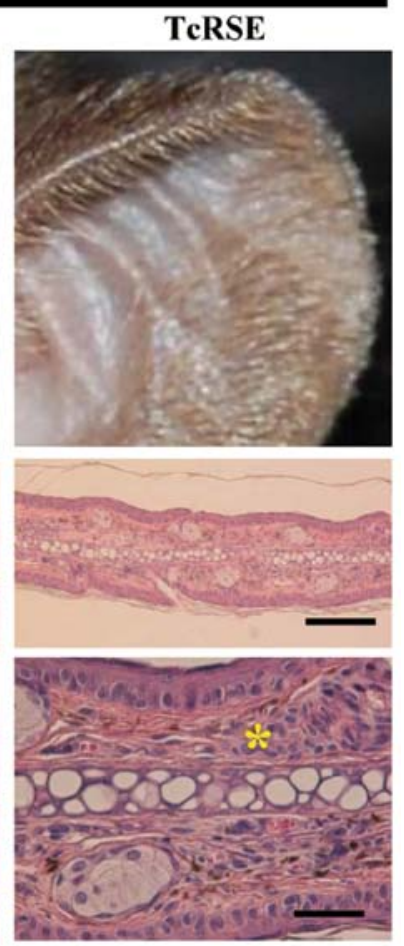

Figure 1. Comparisons of inhibitory features by an aqueous seed extract of Terminalia chebula Retzius (TcRSE) on DNFB-induced ear swelling in C57BL/6 mice. A DNFB solution was applied to a segment of clipped mouse abdominal skin. After initial sensitization, a cutaneous reaction was evoked in the skin of the ear by repeated application of $50 \mu \mathrm{l}$ amounts of $0.2 \%(\mathrm{w} / \mathrm{v})$ DNFB solution on four occasions every 3 days for 2 weeks, commencing 5 days after initial sensitization. Control (vehicle-only) mice were similarly treated with acetone (thus without DNFB). TcRSE was used at a concentration of $100 \mu \mathrm{g} / \mathrm{ml}$. (A) Ear thickness as a measure of the immune response, with and without TcRSE treatment after DNFB sensitization. (B) H\&E staining shows the immune events in ear tissues. Asterisks indicate H\&E-positive cells. Scale bars: $200 \mu \mathrm{m}$ (upper panel); $50 \mu \mathrm{m}$ (lower panel).

$65 \pm 5 \%$. All procedures complied with the Guiding Principles for the Care and Use of Animals (National Research Council, 1996), the rules and in-house guidelines for animal experiments including ethical care as promulgated by our University Committee (20), and the guidelines of the Committee of the International Association for the Study of Pain; Research and Ethical Issues (21). Animals acclimated to the laboratory environment for at least 1 week prior to experimentation. The number of mice in each experimental group was five.

Preparation and fractionation of samples. Seeds of Terminalia chebula Retzius were obtained from a farm in Yeongcheon, Korea. Fruits were sliced, and about $200 \mathrm{~g}$ of crude fruit was extracted with $600 \mathrm{ml}$ distilled water, using a commercial extractor (DWP-3800T; Daewoong Co., Seoul, Korea). The seed extract was filtered, lyophilized, and finally resuspended to yield a $1 \%(\mathrm{w} / \mathrm{v})$ aqueous extract $(1.9 \mathrm{~g} / 190 \mathrm{ml})$. The residue was dissolved in an appropriate buffer and adjusted to a concentration of $100 \mathrm{mg} / \mathrm{ml}$, prior to further investigation (22). The seed extract was used in various in vitro and in vivo assays (data not shown). Plant samples were obtained between September and October, 2009, and taxonomic accuracy was confirmed by a senior staff member of the University. Voucher plant specimens have been deposited in the Laboratory of Food Enzyme Biotechnology, KNU (22).

DNFB-induced animal model of atopy. Mice underwent DNFB sensitization, and were subsequently challenged, as previously described (23). In brief, primary sensitization involved the application of $50 \mu \mathrm{l}$ of $0.5 \%$ (w/v) DNFB solution to a segment of clipped abdominal skin. A cutaneous reaction was evoked in the skin of the ear by repeated applications of $20 \mu 10.2 \%(\mathrm{w} / \mathrm{v})$ DNFB solution. The DNFB challenge was repeated four times every 3 days for 2 weeks, beginning 5 days after initial sensitization (thus on Days 5, 8, 11 and 14). Vehicle mice were similarly treated with acetone, thus without DNFB. Extracts were topically administered on eight occasions (Days 6, 7, 9, 10, 12, 13, 15 and 16), once a day for 2 weeks, commencing the day after the first DNFB re-sensitization (Day 6) for DNFB challenge.

Immunohistochemistry. Ear tissue was fixed for $24 \mathrm{~h}$ in $10 \%$ (v/v) neutral buffered formalin and processed as described elsewhere $(20,23,24)$. In brief, paraffin sections were placed on Probe-On slides and incubated with methanol containing $3 \%(\mathrm{v} / \mathrm{v})$ hydrogen peroxide, to inhibit endogenous peroxidase activity. Tissue sections were next treated with $10 \%(\mathrm{v} / \mathrm{v})$ normal goat serum for $1 \mathrm{~h}$ at room temperature, to block nonspecific antibody binding. Slides were subsequently incubated overnight at $4^{\circ} \mathrm{C}$ with rabbit anti-mouse MMP-9, anti-IL-31 or anti-T-bet.

Statistical analysis. Data are expressed as means \pm standard deviations. Statistical significance was determined using Student's t-test or an ANOVA test of independent means, using a program written in Microsoft Excel (25). The critical level for significance was set at $\mathrm{P}<0.05$. 
A

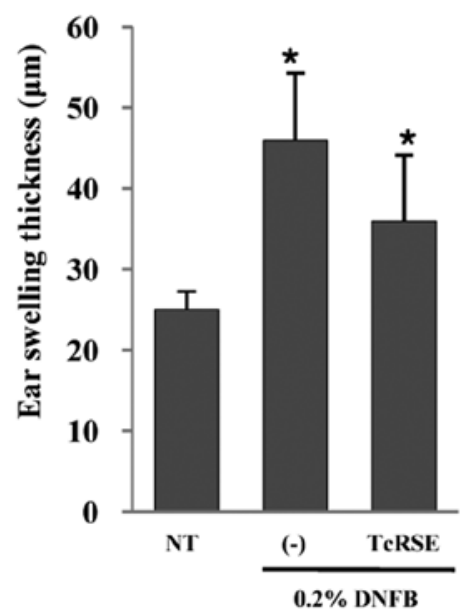

B

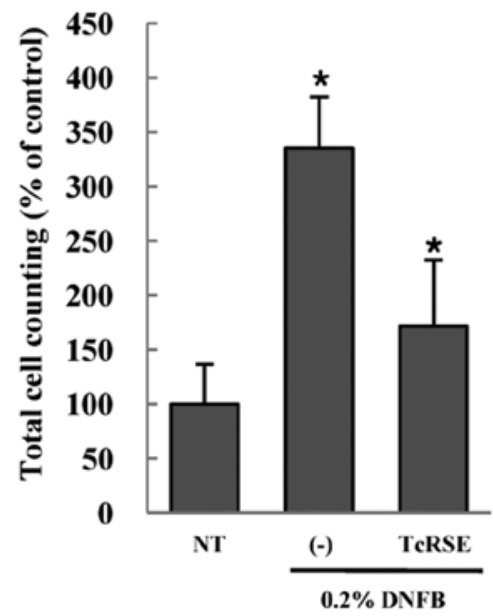

C

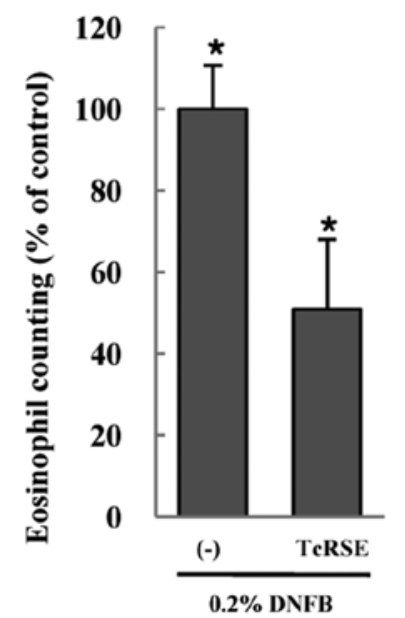

Figure 2. Effects of an aqueous seed extract of Terminalia chebula Retzius (TcRSE) on DNFB-induced atopic inflammation in C57BL/6 mice. A 0.2\% (w/v) DNFB solution was applied to the mouse skin as described in Fig. 1 legend. Control (vehicle-only) mice were similarly treated with acetone (thus without DNFB). TcRSE was used at a concentration of $100 \mu \mathrm{g} / \mathrm{ml}$. (A) Alleviation of ear swelling by application of TcRSE. Thickness was measured using a Vernier caliper (AMI, Painesville, $\mathrm{OH}$ ). Data are expressed as means \pm standard deviations $(\mathrm{n}=5)$; ${ }^{*} \mathrm{P}<0.05$. (B and $\left.\mathrm{C}\right) \mathrm{Decreases}$ in total cell numbers or eosinophils in DNFB-treated ear tissue upon application of TcRSE. Cells were counted by phase contrast microscopy in nine blocks of a hematocytometer, and compared with control values. Data are expressed as means \pm standard deviations $(n=5) ;{ }^{*} \mathrm{P}<0.05$.

\section{Results}

Effect of an aqueous seed extract of Terminalia chebula Retzius on the DNFB-induced ear swelling response. We investigated whether TcRSE protected ear skin damage in mice from exposure to DNFB, which induces allergic dermatitis. First, we assessed whether TcRSE might mitigate DNFB-induced atopic symptoms. Immunohistochemical analysis showed that TcRSE could alleviate DNFB-induced atopic symptoms in mice. DNFB $(0.2 \%, \mathrm{w} / \mathrm{v})$ re-sensitization caused severe scarring and eczema of ear skin, but treatment with TcRSE $(100 \mu \mathrm{g} / \mathrm{ml})$ resulted in rapid recovery and alleviation of the classical symptoms of atopic dermatitis (Fig. 1, see the arrowheads in the middle and right photos). To confirm these protective effects, we measured the ear swelling thickness. The thickness in control animals was $26.3 \pm 1.2 \mu \mathrm{m}$, whereas that in DNFB-treated animals was 2.1-fold higher (Fig. 1B). This increase was significantly inhibited, to a final level of 52\% that of the control group, upon application of TcRSE. This indicates that TcRSE affects the dermal microenvironment.

Histochemical analysis of the tissues. We next removed and sectioned ear tissue, and histochemically evaluated immune cell numbers during DNFB-induced inflammation. Fig. 1A shows control mice with normal ear thickness and no clinical abnormalities (top and bottom portions of the left columns). After DNFB treatment, inflammation was evident, ear thickness increased, and obvious scarring and eczema appeared (Figs. 1 and 2A). Stained inflammatory cell numbers increased (asterisks in Figs. 1B and 2A). However, the expression level of inflammation-associated cells was markedly reduced upon treatment with TcRSE $(100 \mu \mathrm{g} / \mathrm{ml})$, as shown by H\&E staining of sections at magnifications of both 100 and 400 (left photographs in the top and bottom columns of Fig. 1B). Total cell counts showed that DNFB induction resulted in a 3.4-fold increase in inflammatory cell number, whereas the level in TcRSE-treated animals decreased to $69.5 \%$ that of the control (Fig. 2B). Eosinophil levels were 10.6 \pm 1.1 cells/ block in the DNFB-alone group, and $5.4 \pm 1.8$ cells/block in the TcRSE-treated group (Fig. 2C). This 50.2\% decrease in eosinophil number indicates that TcRSE inhibits eosinophil accumulation (Fig. 2C).

Matrix metalloproteinase expression during the onset. We, therefore, immunohistochemically investigated whether TcRSE affected MMP activity. The results of tests in which MMP-9 expression after DNFB-induced atopic triggering was evaluated are shown in Fig. 3A and D. Notably, MMP-9 expression level after TcRSE $(100 \mu \mathrm{g} / \mathrm{ml})$ treatment was markedly reduced compared with that of the DNFB-induced group, suggesting that TcRSE can inhibit DNFB-induced skin erosion. Other MMPs, such as MMP-2 or MMP-3, were not significantly changed at concentrations up to $100 \mu \mathrm{g} / \mathrm{ml}$ (data not shown).

Expression of Th cell-specific biomarkers. We further examined whether TcRSE could ameliorate skin lesions. As shown in Fig. 3B and E, the level of IL-31-positive cells decreased by approximately $44.1 \%$ after TcRSE application (Fig. 3B and E). However, T-bet application had the opposite effect. The use of T-bet-positive cells (Fig. 3C and F) confirmed these observations.

\section{Discussion}

Terminalia chebula originates in Southeast Asia, and the ripe fruit has laxative, diuretic, and anti-oxidative qualities. In addition, a prodrug activity for treatment of cardiovascular disorders has been described (9-13). An aqueous seed extract of Terminalia chebula Retzius (TcRSE) exhibits in vitro antioxidant and free radical-scavenging behavior, and has potent antimicrobial, 
A

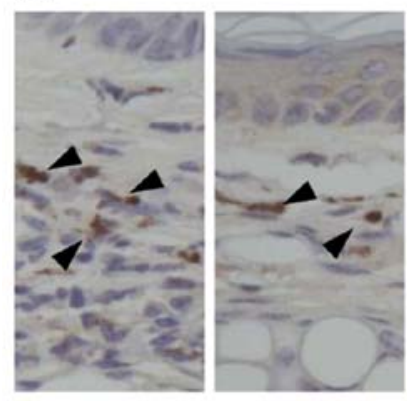

D

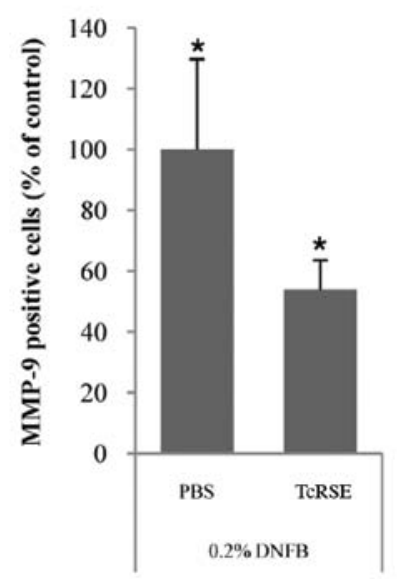

B

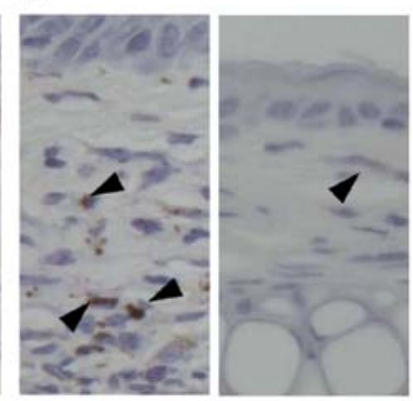

E

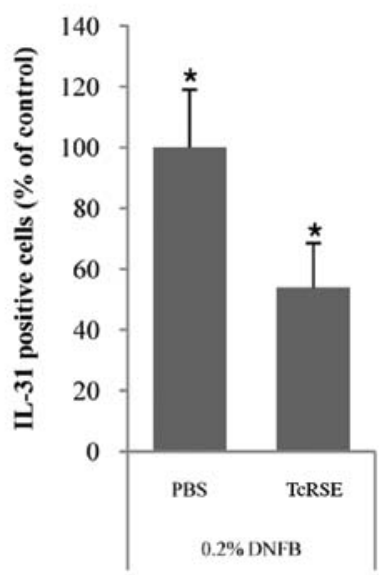

C

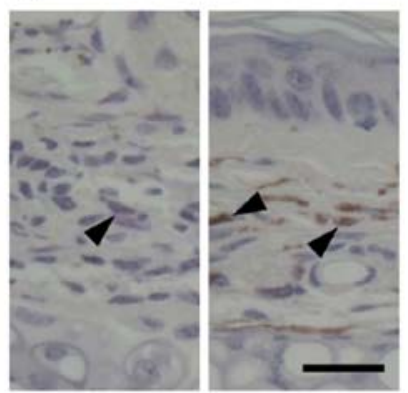

F

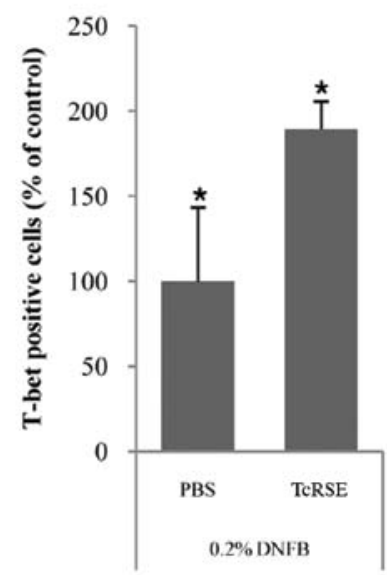

Figure 3. Inhibition of atopic dermatitis-related biomarker expression with or without application of an aqueous extract of Terminalia chebula Retzius. The levels of MMP-9-(D), IL-31-(E) and T-bet-(F) positive cells in DNFB-treated mice, either exposed to TcRSE or not, were assayed. Arrowheads indicate cells expressing these proteins (A, B and C). Cells were photographed under a phase contrast microscope, and showed classical morphology. (D and E) Data are expressed as the means \pm standard deviations $(\mathrm{n}=5)$; ${ }^{*} \mathrm{P}<0.05$. Scale bar, $25 \mu \mathrm{m}$.

anticancer, antiviral, and anti-diabetic effects either in vitro or in vivo (14). However, to date, the immune-related activities of TcRSE have not been well characterized, and any protective effect of TcRSE on atopic dermatitis remains undescribed. Therefore, in this study, we addressed the biological activities of TcRSE on DNFB-induced atopic dermatitis symptoms using a mouse model.

There are many reports on anti-atopic dermatitis activities of various phytochemicals. PG102, an aqueous extract from Actinidia arguta (26), is an example exhibiting such an activity. White rose fetal extract of Rosa rugosa root (27), procyanidin C1 from apple (28), and hot water extract of Cydonia oblonga (29) have shown potential in inhibiting chemical-induced animal model or NC/Nga mice. In the course of screening of anti-atopic agents, we found that an aqueous TcRSE exhibits in vitro antioxidant and free radical-scavenging capability, and has potent T-bet promoter enhancing activity.

In the present study we have shown that TcRSE ameliorates ear skin damage in mice from exposure to DNFB, an inducer of allergic dermatitis, and moreover confirmed that TcRSE alleviated DNFB-induced atopic symptoms in DNFBtreated mice by histological analysis (Figs. 1 and 2). At the preliminary step, to further identify the active compound in TcRSE, we prepared the 10 fractions as water-methanol fractions by increasing polarity between water and methanol, followed by collection of 10 fractions. Thereafter, we checked the in vitro anti-atopic activity by measuring $\operatorname{IgE}$ secretion of total spleenic $\mathrm{T}$ cells in normal mice. Results of an ELISA assay showed that only the aqueous fraction $(>90 \%)$ had strong activity in inhibiting secreting $\operatorname{IgE}$ (data not shown). As we could not detect any activities by other non-polar solvent systems, we, thereafter, used an aqueous fraction in the in vivo animal experiment and demonstrate that the treatment mitigated the DNFB-induced atopic symptoms in mice. Morphological changes during DNFB-induced atopic model should be verified by various molecular inflammation markers. Therefore, we scrutinized inflammation-related markers such as MMP-9, IL-31 and T-bet by immunohistochemical analyses.

The balance between MMP levels is principally responsible for remodeling of skin tissue (18). Various pathological conditions are caused by imbalances between the levels of MMPs and inhibitors in the skin. In both remodeling and disease, it appears that erosion of or eczema development in the skin epithelium is associated with overexpression of MMP-1, -3, -8, -9 and/or -13 (19). In particular, MMP-8 and MMP-9 play pivotal roles in skin remodeling and reconstruction during a chemically-induced inflammatory response (24). We confirmed that a decrease in the MMP-9 expression level was definitely detected in TcRSE treated mice (Fig. 3). Our results are in agreement with those of other researchers in that MMP-9 expression is a recognizable molecular inflammation 
marker in clinical and/or in vitro atopic dermatitis or asthma symptoms $(30,31)$.

It is also documented that IL-31, preferentially produced by T-helper-type 2 (Th2) cells, is overexpressed upon development of severe pruritus, alopecia, and skin lesions (32). Furthermore, IL-31 receptor expression was increased in diseased tissues in an animal model of allergic dermatitis and airway hypersensitivity (33). There is evidence that IL-31 is up-regulated in atopic dermatitis skin lesions in humans and in skin lesion-induced mice and therefore, IL-31 might present a novel target for anti-inflammatory options in the treatment of atopic dermatitis $(34,35)$. In our data, we also confirmed the expression of IL-31 expression between DNFB-challenged mice with or without TcRSE treatment (Fig. 3B). Previously, we constructed a cell line stably harboring a gene under the control of the T-bet promoter, to select mutations activating the promoter gene, resulting in a regulation of the balance between Th1 and Th2 cells (20). By using the stable cell line, we observed a positive result with the same pattern as above (Fig. 3A-C), indicating that TcRSE regulated the development of atopic dermatitis by increasing Th1 cells rather than Th 2 cells, resulting in a balance between the cell subsets. T-bet is a unique transcription factor expressed during the differentiation of both Th1 and Th2 cells, and has recently been specifically associated with asthmatic symptoms in children $(36,37)$. Therefore, it is probable that anti-asthmatic compounds/extracts from Helianthus annuus, Camellia sinensis, or Spinacia oleracea may also mitigate atopic symptoms in mice $(20,38,39)$. Other reports indicate that chebulagic acid, chebulanic acid, and triterpene alcohol also contained the extracts/fractions in the leaf/TcRSE. We cannot rule out the possibility that the extract contains the agents, but at least in our preliminary test from the purified chebulagic acid and chebulanic acid (40), the activities were not detectable. Therefore, this is the reason that we used the aqueous fraction throughout the experiment, although the identification of polar compound(s) should be purified.

In summary, we found that TcRSE inhibited DNFBinduced atopic inflammation by reducing MMP-9 level and IL-31 activity, and by stimulating T-bet action. The data show that TcRSE may control expression of atopic molecular markers by adjusting the balance of expression between Th cell subsets. Thus, atopic dermatitis may be ameliorated by precise targeting of atopic dermatitis-associated molecules, and a useful medication for treatment of the condition may be formulated from herb and/or food biomaterial(s).

\section{Acknowledgements}

This study was supported by a Technology Development Program for Agriculture and Forestry, Ministry of Agriculture and Forestry, Republic of Korea (on in vitro anti-allergic assays), and partially supported by a Kyungpook National University Research Fund (S.-H.L.). We appreciate Si-Rim Lee, Hyun Jin Lee, Eun-Young Kwon, Chul-Hong Park, and Hyeong-U Son for their technical assistance.

\section{References}

1. Ahmad I, Mehmood Z and Mohammad F: Screening of some Indian medicinal plants for their antimicrobial properties. J Ethnopharmacol 62: 183-193, 2008.
2. Holst B and Williamson G: Nutrients and phytochemicals: from bioavailability to bioefficacy beyond antioxidants. Curr Opin Biotechnol 19: 73-82, 2008

3. Srikumar R, Parthasarathy NJ, Shankar EM, Manikandan S, Vijayakumar R. Thangaraj R, Vijayananth K, Sheeladevi R and Rao UA: Evaluation of the growth inhibitory activities of Triphala against common bacterial isolates from HIV-infected patients. Phytother Res 21: 476-480, 2007.

4. Cheng HY, Lin TC, Yu KH, Yang CM and Lin CC: Antioxidant and free radical scavenging activities of Terminalia chebula. Biol Pharm Bull 26: 1331-1335, 2003.

5. Lee HS, Jung SH, Yun BS and Lee KW: Isolation of chebulic acid from Terminalia chebula Retz. and its antioxidant effect in isolated rat hepatocytes. Arch Toxicol 81: 211-218, 2007.

6. Na M, Bae K, Kang SS, Min BS, Yoo JK, Kamiryo Y, Senoo Y, Yokoo S and Miwa N: Cytoprotective effect on oxidative stress and inhibitory effect on cellular aging of Terminalia chebula fruit. Phytother Res 18: 737-741, 2004.

7. Naik GH, Priyadarsini KI, Naik DB, Gangabhagirathi R and Mohan H: Studies on the aqueous extract of Terminalia chebula as a potent antioxidant and a probable radioprotector. Phytomedicine 11: 530-538, 2004.

8. Naik GH, Priyadarsini KI, Bhagirathi RG, Mishra B, Mishra KP Banavalikar MM and Mohan $\mathrm{H}$ : In vitro antioxidant studies and free radical reactions of triphala, an ayurvedic formulation and its constituents. Phytother Res 19: 582-586, 2005.

9. Kim HG, Cho JH, Jeong EY, Lim JH, Lee SH and Lee HS: Growth-inhibiting activity of active component isolated from Terminalia chebula fruits against intestinal bacteria. J Food Prot 69: 2205-2209, 2006.

10. Malekzadeh F, Ehsanifar H, Shahamat M, Levin M and Colwell RR: Antibacterial activity of black myrobalan (Terminalia chebula Retz.) against Helicobacter pylori. Int J Antimicrob Agents 18: 85-88, 2001.

11. Ahn MJ, Kim CY, Lee JS, Kim TG, Kim SH, Lee CK, Lee BB, Shin CG, Huh H and Kim J: Inhibition of HIV-1 integrase by galloyl glucoses from Terminalia chebula and flavonol glycoside gallates from Euphorbia pekinensis. Planta Med 68: 457-459, 2002.

12. Vonshak A, Barazani O, Sathiyamoorthy P, Shalev R, Vardy D and Golan-Goldhirsh A: Screening South Indian medicinal plants for antifungal activity against cutaneous pathogens. Phytother Res 17: 1123-1125, 2003.

13. Prasad L,Husain KT, JahangirT and Sultana S: Chemomodulatory effects of Terminalia chebula against nickel chloride induced oxidative stress and tumor promotion response in male Wistar rats. J Trace Elem Med Biol 20: 233-239, 2006.

14. Srikumar R, Parthasarathy NJ, Manikandan S, Narayanan GS and Sheeladevi R: Effect of Triphala on oxidative stress and on cellmediated immune response against noise stress in rats. Mol Cell Biochem 283: 67-74, 2006.

15. Lee HS, Won NH, Kim KH, Lee H, Jun W and Lee KW: Antioxidant effects of aqueous extract of Terminalia chebula in vivo and in vitro. Biol Pharm Bull 28: 1639-1644, 2005.

16. Harper JI, Godwin H, Green A, Wilkes LE, Holden NJ, Moffatt M, Cookson WO, Layton $\mathrm{G}$ and Chandler S: A study of matrix metalloproteinase expression and activity in atopic dermatitis using a novel skin wash sampling assay for functional biomarker analysis. Br J Dermatol 162: 397-403, 2010.

17. Boguniewicz $M$ and Leung DY: Genetic variants in thymic stromal lymphopoietin are associated with atopic dermatitis and eczema herpeticum. J Allergy Clin Immunol 125: 4-13, 2010.

18. Hanifin JM: Evolving concepts of pathogenesis in atopic dermatitis and other eczemas. J Invest Dermatol 129: 320-322, 2009.

19. Kähäri VM and Saarialho-Kere U: Matrix metalloproteinases in skin. Exp Dermatol 6: 199-213, 1997.

20. Heo JC, Woo SU, Kweon MA, Park JY, Lee HK, Son M, Rho JR and Lee SH: Aqueous extract of the Helianthus annuus seed alleviates asthmatic symptoms in vivo. Int J Mol Med 21: 57-61, 2008.

21. Zimmermann M: Ethical guidelines for investigations of experimental pain in conscious animals. Pain 16: 109-110, 1983.

22. Lee SH: An extract from Terminalia chebula Retzius for prophylaxis or treatment to dermatitis and a pharmaceutical composition comprising the same as an effective component. Korea Patent Application 10-2010-0028242, pp1-21, 2010.

23. Inagaki N, Shiraishi N, Igeta K, Itoh T, Chikumoto T, Nagao M, Kim JF and Nagai H: Inhibition of scratching behavior associated with allergic dermatitis in mice by tacrolimus, but not by dexamethasone. Eur J Pharmacol 546: 189-196, 2006. 
24. Parks WC, Wilson CL and López-Boado YS: Matrix metalloproteinases as modulators of inflammation and innate immunity. Nat Rev Immunol 4: 617-629, 2004.

25. Kim DY, Ryu SY, Lim JE, Lee YS and Ro JY: Anti-inflammatory mechanism of simvastatin in mouse allergic asthma model. Eur J Pharmacol 557: 76-86, 2007.

26. Kim D, Kim SH, Park EJ, Kang CY, Cho SH and Kim S: Antiallergic effects of PG102, a water-soluble extract prepared from Actinidia arguta, in a murine ovalbumin-induced asthma model. Clin Exp Allergy 39: 280-289, 2009.

27. Jeon JH, Kwon SC, Park D, Shin S, Jeong JH, Park SY, Hwang SY, Kim YB and Joo SS: Anti-allergic effects of white rose petal extract and anti-atopic properties of its hexane fraction. Arch Pharm Res 32: 823-830, 2009

28. Nakano N, Nishiyama C, Tokura T, Nagasako-Akazome Y, Ohtake Y, Okumura K and Ogawa H: Procyanidin C1 from apple extracts inhibits Fc epsilon RI-mediated mast cell activation. Int Arch Allergy Immunol 147: 213-221, 2008.

29. Shinomiya F, Hamauzu Y and Kawahara T: Anti-allergic effect of a hot-water extract of quince (Cydonia oblonga). Biosci Biotechnol Biochem 73: 1773-1778, 2009.

30. Devillers A, van Toorenenbergen AW, Klein-Heerenbrink GJ, Muldert PG and Oranje AP: Elevated levels of plasma matrix metalloproteinases-9 in patients with atopic dermatitis: a pilot study. Clin Exp Dermatol 32: 311-313, 2007.

31. Belleguic C, Corbel M, Germain N, Lena H, Boichot E, Delaval PH and Lagente V: Increased release of matrix metalloproteinase-9 in the plasma of acute severe asthmatic patients. Clin Exp Allergy 32: 217-223, 2002.

32. Dillon SR, Sprecher C, Hammond A, Bilsborough J, RosenfeldFranklin M, Presnell SR, Haugen HS, Maurer M, Harder B, Johnston J, Bort S, Mudri S, Kuijper JL, Bukowski T, Shea P, Dong DL, Dasovich M, Grant FJ, Lockwood L, Levin SD, LeCiel C, Waggie K, Day H, Topouzis S, Kramer J, Kuestner R, Chen Z, Foster D, Parrish-Novak J and Gross JA: Interleukin 31, a cytokine produced by activated $\mathrm{T}$ cells, induces dermatitis in mice. Nat Immunol 5: 752-760, 2004.
33. Takaoka A, Arai I, Sugimoto M, Yamaguchi A, Tanaka M and Nakaike S: Expression of IL-31 gene transcripts in NC/Nga mice with atopic dermatitis. Eur J Pharmacol 516: 180-181, 2005.

34. Grimstad O, Sawanobori Y, Vestergaard C, Bilsborough J, Olsen UB, Grønhøj-Larsen C and Matsushima K: Anti-interleukin31-antibodies ameliorate scratching behaviour in NC/Nga mice: a model of atopic dermatitis. Exp Dermatol 18: 35-43, 2009.

35. Raap U, Wichmann K, Bruder M, Ständer S, Wedi B, Kapp A and Werfel T: Correlation of IL-31 serum levels with severity of atopic dermatitis. J Allergy Clin Immunol 122: 421-423, 2008.

36. Lametschwandtner G, Biedermann T, Schwärzler C, Günther C, Kund J, Fassl S, Hinteregger S, Carballido-Perrig N, Szabo SJ, Glimcher LH and Carballido JM: Sustained T-bet expression confers polarized human Th2 cells with Th1-like cytokine production and migratory capacities. J Allergy Clin Immunol 113: 987-994, 2004

37. Szabo SJ, Kim ST, Costa GL, Zhang XC, Fathman G and Glimcher LH: A novel transcription factor, T-bet, directs Th1 lineage commitment. Cell 100: 655-669, 2000.

38. Heo JC, Rho JR, Kim TH, Kim SY and Lee SH: An aqueous extract of green tea Camellia sinensis increases expression of Th1 cell-specific anti-asthmatic markers. Int J Mol Med 22: 763-767, 2008.

39. Heo JC, Park CH, Lee HJ, Kim SO, Kim TH and Lee SH: Amelioration of asthmatic inflammation by an aqueous extract of Spinacia oleracea Linn. Int J Mol Med 25: 409-414, 2010.

40. Gao H, Huang YN, Gao B and Kawabata J: Chebulagic acid is a potent alpha-glucosidase inhibitor. Biosci Biotechnol Biochem 72: 601-603, 2008. 